(2) Open Access Full Text Article

\title{
Endoperoxide antimalarials: development, structural diversity and pharmacodynamic aspects with reference to I,2,4-trioxane-based structural scaffold
}

This article was published in the following Dove Press journal:

Drug Design, Development and Therapy

I November 2016

Number of times this article has been viewed

\section{Mithun Rudrapal \\ Dipak Chetia}

Department of Pharmaceutical Sciences, Dibrugarh University, Dibrugarh, India
Correspondence: Mithun Rudrapal Department of Pharmaceutical Sciences, Dibrugarh University, Dibrugarh 786 004, Assam, India

Tel +9l 3732370254

$\mathrm{Fax}+913732370323$

Email rs_rudrapal@yahoo.co.in
Abstract: Malaria disease continues to be a major health problem worldwide due to the emergence of multidrug-resistant strains of Plasmodium falciparum. In recent days, artemisinin (ART)-based drugs and combination therapies remain the drugs of choice for resistant $P$. falciparum malaria. However, resistance to ART-based drugs has begun to appear in some parts of the world. Endoperoxide compounds (natural/semisynthetic/synthetic) representing a huge number of antimalarial agents possess a wide structural diversity with a desired antimalarial effectiveness against resistant $P$. falciparum malaria. The 1,2,4-trioxane ring system lacking the lactone ring that constitutes the most important endoperoxide structural scaffold is believed to be the key pharmacophoric moiety and is primarily responsible for the pharmacodynamic potential of endoperoxide-based antimalarials. Due to this reason, research into endoperoxide, particularly 1,2,4-trioxane-, 1,2,4-trioxolane- and 1,2,4,5-teraoxane-based scaffolds, has gained significant interest in recent years for developing antimalarial drugs against resistant malaria. In this paper, a comprehensive effort has been made to review the development of endoperoxide antimalarials from traditional antimalarial leads (natural/semisynthetic) and structural diversity of endoperoxide molecules derived from 1,2,4-trioxane-, 1,2,4-trioxolane- and 1,2,4,5-teraoxanebased structural scaffolds, including their chimeric (hybrid) molecules, which are newer and potent antimalarial agents.

Keywords: endoperoxide, structural diversity, 1,2,4-trioxane, pharmacophore, pharmacodynamic, antimalarial

\section{Introduction}

Malaria is a lethal infectious disease which continues to be a major problem to public health across the world. According to the World Health Organization (WHO), approximately $40 \%$ of the world population lives in malaria endemic regions, with around 200-300 million clinical cases and about 0.44 million deaths per year globally. Most of the malaria-related deaths occur among children under the age of five and pregnant women. ${ }^{1}$ The disease is caused by protozoan parasites of the genus Plasmodium. Five well-known species (Plasmodium falciparum, Plasmodium vivax, Plasmodium malariae, Plasmodium ovale and Plasmodium knowlesi) have been reported so far to be the causative organisms of malaria in human. Among these five organisms, $P$. falciparum is the most widespread and pernicious species which causes potentially fatal malaria such as cerebral malaria and most of the malaria-related deaths worldwide. ${ }^{2-4}$ In patients with severe and complicated malaria caused by $P$. falciparum, the mortality rate accounts for 20\%-50\% when left untreated. ${ }^{1} P$. falciparum also produces a varying degree of resistance against a majority of existing antimalarial 
therapies. The emergence and spread of multidrug-resistant strains of $P$. falciparum against currently available antimalarial drugs has become an increasingly serious concern in the treatment of malaria. ${ }^{5-7}$

\section{Artemisinin (ART)-based antimalarials: therapies, issues and challenges}

ART (1a) was isolated (1972) from the decoction of leaves of Artemisia annua (Sweet wormwood), a medicinal plant (qinghaosu) that has been used for over 2,000 years in the Chinese Traditional Medicine to treat fever. Chemically, ART is a sesquiterpene lactone-bearing 1,2,4-trioxane ring system as the peroxide functional moiety (endoperoxide) within the ring system of a whole molecule. Although ART had been used clinically to treat multidrug-resistant $P$. falciparum malaria, its therapeutic potential was limited owing to its low solubility in both oil and water. Later, reduction of ART produced dihydroartemisinin (DHA, 1b), a sesquiterpene lactol, which served as a template for the synthesis of a series of semisynthetic analogs such as artemether (1c), arteether (1d), artesunate (1e) and artelininic acid (1f). They are collectively known as the first-generation derivatives of ART (Figure 1).

The first-generation ART derivatives can be grouped into oil-soluble $C(10) \beta$-alkyl ethers (artemether and arteether) and water-soluble $\mathrm{C}(10) \beta$-(substituted) esters (sodium artesunate and sodium artelinate). These drugs possess more oil/water solubility and antimalarial efficacy than the parent drug, ART. Due to these reasons, they mostly replaced the quinoline-based drugs such as quinine (QN), chloroquine (CQ), amodiaquine and mefloquine (MQ) and their combination therapies (with non-quinolines like sulfadoxine, proguanil, pyrimethamine, atovaquone and antibiotics) in the treatment of malaria. ${ }^{8-14}$

The first-generation ART derivatives are some successful drugs that have been found to be effective against
CQ-resistant P. falciparum malaria. Therefore, they represent a new class of antimalarial therapeutics. These semisynthetic derivatives were developed in order to improve solubility and overcome pharmacokinetic issues that are commonly associated with the parent molecule, ART. These drugs are usually administered by oral or parenteral route to treat both uncomplicated and complicated (P. falciparum and $P$. vivax) malaria in many countries of the world. Artemether and arteether are more potent than ART but have shorter biological half-lives, and produce fatal toxicities such as hematopoietic, cardiac and central nervous system (CNS) toxicities (in animal model). ${ }^{15,16}$ The sodium salt of artesunic acid (water-soluble derivative of ART) is capable of rapidly reducing parasitemia in patients with severe complicated malaria (eg, cerebral malaria). Artesunate injection has been attributed to give about $92 \%$ cure rate if given once per day for seven days. But, to stop the spread of resistance, sodium artesunate is usually given in combination with more slowly eliminated drugs, such as lumefantrine (2a, 9-phenanthrenemethanols), amodiaquine (2b), piperaquine (2c, 4-aminoquinolines [AQs]), MQ (2d, 4-quinolinemethanol) and pyronaridine (2e, benzonaphthyridine derivative). This in turn increases the efficiency of treatment in resistant malaria. ${ }^{17-19}$ The structures of these drugs are given in Figure 2.

Sodium artelinate, the sodium salt of artelinic acid, is sometimes used in the place of artesunate to overcome the hydrolytic instability experienced with the latter. In comparison to oil-soluble analogs (artemether and arteether), sodium artelinate is not only more stable in aqueous solution but also has a much longer biological half-life (1.5-3.0 h) with less CNS toxicity (in rats). The water-soluble ART derivatives have a rapid onset of action which makes them especially effective against severe malaria. At the same time, rapid disappearance from the blood may be a key reason behind their slow development of resistance against malaria parasites. It may also be a reason for recrudescence when these drugs

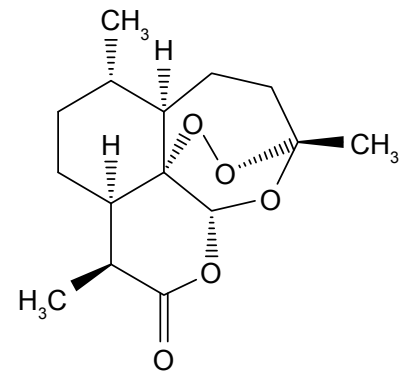

$1 \mathbf{a}$

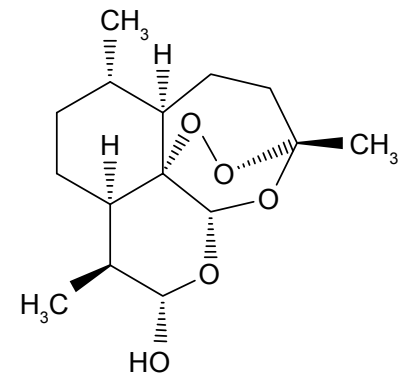

$1 \mathrm{~b}$

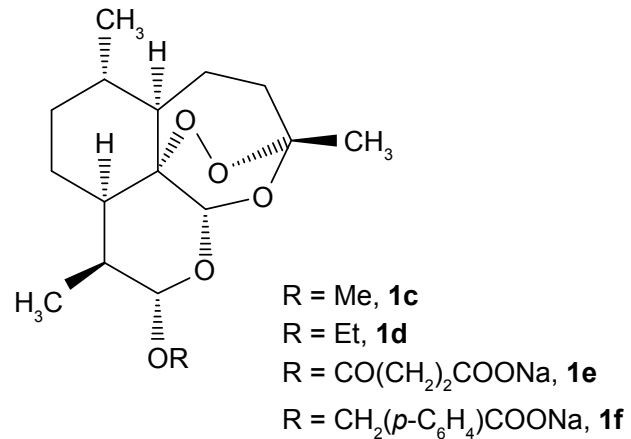

Figure I Artemisinin and its first-generation derivatives. 


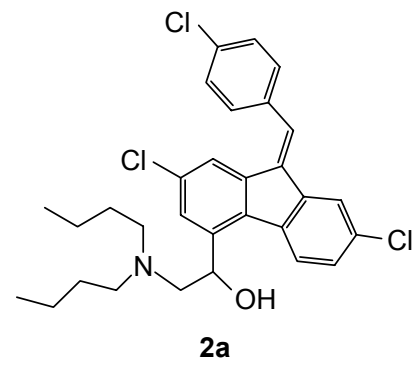

2a<smiles>CCN(CC)Cc1cc(Nc2ccnc3cc(Cl)ccc23)ccc1O</smiles>

$2 \mathbf{b}$

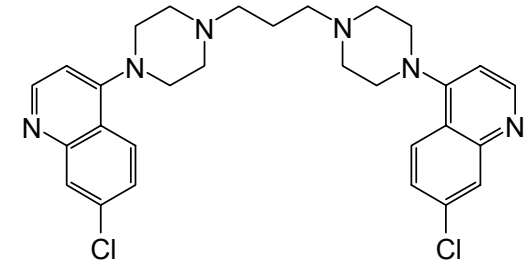

2c

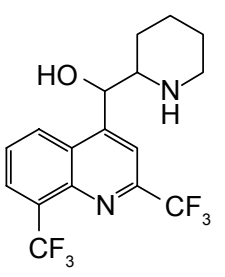

2d

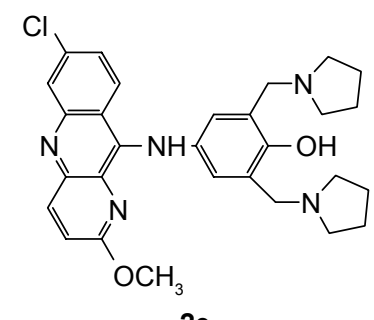

$2 \mathrm{e}$

Figure 2 Some important drugs used in combination with artesunate.

are used alone in monotherapy. ${ }^{15,19}$ Fast-acting ART-based compounds are therefore often given in combination with a second potent drug from a different antimalarial class. Such combination antimalarial therapies are known as ART-based combination therapies (ACTs). According to the WHO, ACTs are currently considered as the frontline treatment of multidrug-resistant $P$. falciparum malaria. ${ }^{11,12}$

However, resistance to ACTs (eg, artesunate-MQ) against $P$. falciparum has been observed in many parts (Southeast Asia) of the world. Recently, resistance against piperaquine is also being found for $P$. falciparum parasite. Due to this reason, triple ACTs such as artemether + lumefantrine + amodiaquine and artesunate $+\mathrm{MQ}+$ piperaquine have been recommended by the WHO for resistant $P$. falciparum malaria. Some of these combination therapies (eg, artesunate $+\mathrm{MQ}+$ piperaquine) have shown positive results in TRACII study. Since MQ is active in piperaquineresistant strains and vice versa, this triple-drug regimen can be an effective therapeutic approach to treat resistant malaria. ${ }^{20}$ High treatment cost (relative to CQ or QN), unsatisfactory physicochemical/pharmacokinetic properties (poor lipid-/ water-partitioning behavior, inadequate bioavailability, short plasma half-life, etc.), toxicities and lower abundance (limited availability from natural sources) are some other notable problems associated with ART-based antimalarials. ${ }^{19,21,22}$ Due to these issues, the treatment of malaria has become a challenging task, which urges the discovery and development of novel antimalarial agents for the treatment of resistant malaria. The clinical utility of ACTs is due to their rapid onset of action and potent antiparasitic activity of the ART endoperoxide component. Though ART endoperoxides and their derivatives are the mainstay of current therapy, the emergence of resistance to ART-based drugs is a potential problem which is adversely affecting clinical outcomes of malaria treatment in developing countries. In recent years, research into endoperoxide scaffold of ART has been carried out for the development of newer antimalarial agents. Several design strategies for the development of affordable and effective synthetic alternatives to ART have already been initiated by the Medicines for Malaria Venture (MMV) program in 2002 with financial support. Such endoperoxidebased synthetic antimalarial agents would prevent disease resistance while providing better treatment options over ART and/or ACTs and acting as effective as artesunate, at an affordable price and with easy availability. The aim of synthetic peroxide discovery project of MMV is to identify a new class of synthetic, new-generation and orally active peroxides, which are more potent (with improved physicochemical properties and better efficacy profile in ARTresistant strains) than the available semisynthetic ARTs for the treatment of uncomplicated $P$. falciparum malaria. The purpose of this project is to provide a low-cost treatment when used in combination and to make the dosing regimen convenient with better patient compliance as compared to some existing therapies. The chemical scaffold of the endoperoxide compound series contains a 1,2,4-trioxolane moiety, referred to as $\mathrm{OZ}$ for ozonide. Therefore, the work of developing synthetic endoperoxides is also known as " $\mathrm{OZ}$ programme" which was first started at the F. Hoffman-La Roche, Switzerland (1980s and 1990s). ${ }^{21-27}$ 


\section{Endoperoxide antimalarials: structural diversity and bioactivity Second-generation endoperoxides}

Hundreds of natural and synthetic peroxide compounds have been developed from the first-generation derivatives of ART. The second-generation derivatives (Figure 3) possess good clinical efficacy against drug-resistant strains of P. falciparum and also have better metabolic stability than first-generation analogs. The second-generation drugs include $\mathrm{C}(10)$ aryloxy derivatives (3a-3d) of artelinic acid, deoxyartemisinin (3e) and its derivatives, $\mathrm{C}(9)$-substituted compounds (3f-3h) and $\mathrm{C}(10)$ heterocyclic derivatives $(\mathbf{3 i}, \mathbf{3 j}, \mathbf{5 i}, \mathbf{5 j}){ }^{19,24}$

\section{Newer synthetic endoperoxides}

Newer semisynthetic and synthetic endoperoxides $(\mathbf{4 a}-\mathbf{4} \mathbf{p})$ are also being developed. Some novel candidates are arteflene (4b), artemisinic acid (4c), artemisitene (4d), SM905 (4e), arterolane (OZ477, 4f), artemeside (4i), artemisone (4l), RW1777 (4n) and artefenomel (OZ439, 4p). ${ }^{11,19}$ The structures are given in Figure 4.

$\mathrm{C}(10)$-ether derivatives $(\mathbf{4 g}-\mathbf{4 h})$ and $\mathrm{C}(10)$-alkylamino analogs $(4 \mathbf{i}-40)$ of ART are also included in this category. These antimalarials are highly effective against severe, resis$\tan P$. falciparum malaria like cerebral malaria. Arteflene is a stable, safe and effective drug, but it shows a certain degree of recrudescence. It is a synthetic derivative obtained from a natural precursor Yingzhaosu A, 4a. ${ }^{11}$ The suppressive activity of arteflene is comparable to $\mathrm{CQ}$ in uncomplicated malaria. But, artemisone is not more potent than artesunate. However, it provides a single-dose cure in Aotus monkeys infected with $P$. falciparum when given in combination with MQ.
Arterolane (OZ477) and artefenomel (OZ439) are two latest synthetic endoperoxides originally developed from the parent structure of Yingzhaosu A as alternative drugs to classical semisynthetic ART derivatives for resistant malaria. Arterolane is an orally active synthetic trioxolane (an ozonide with adamantane residue) analog of ART which has been effective against CQ-resistant strains. These newer drugs are also given in fixed-dose combination with piperaquine (eg, artemisone + piperaquine and arterolane + piperaquine) in uncomplicated P. falciparum-resistant malaria. In clinical trials, a cure rate of about $95 \%$ has been reported for the arterolane-piperaquine fixed-dose combination regimen when given thrice daily for a course of three days alternative to ACTs. On the other hand, artefenomel is a novel synthetic trioxolane derivative which is having fast killing action on ART-resistant parasites. However, its combination with ferroquine has been found active against CQ-, MQ- and piperaquine-resistant $P$. falciparum infection. Artefenomel has also been tested in combination with piperaquine and found to have potent activity on ARTresistant $P$. falciparum strains. ${ }^{25-27}$

Newer endoperoxide drugs also include several 11-azaartemisinins and fluorinated analogs (Figure 5). 11-Azaartemisinins (7a-7f, 5a-5f) are more stable and active than ART. Fluorinated analogs have good oral bioavailability (due to increased lipophilicity) with high metabolic stability. Compound $\mathbf{5 g}$ is a fluorinated derivative of DHA, and compounds $\mathbf{5 h}-\mathbf{5 j}$ are the 10-carba analogs of ART. ${ }^{14,24}$

\section{I,2,4-Trioxane-based and related endoperoxides \\ I,2,4-Trioxane-based}

1,2,4-Trioxane is a biologically important structural scaffold that appears in natural/synthetic endoperoxide molecules and

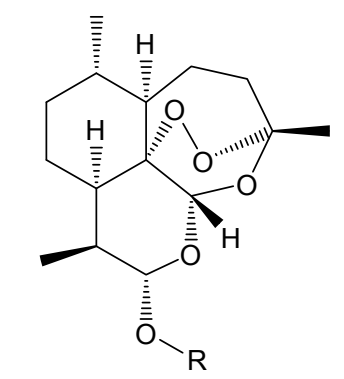

$$
\begin{aligned}
& \mathrm{R}=\mathrm{CH}\left(p-\mathrm{NO}_{2} \mathrm{C}_{6} \mathrm{H}_{4}\right) \mathrm{CO}_{2} \mathrm{Et}, \mathbf{3 a} \\
& \mathrm{R}=\mathrm{CHNH} \mathrm{CH}_{2} \mathrm{CO}_{2} \mathrm{Et}, \mathbf{3} \mathbf{b} \\
& \mathrm{R}=\mathrm{CH}\left(p-\mathrm{CF}_{3} \mathrm{C}_{6} \mathrm{H}_{4}\right), \mathbf{3} \mathbf{c} \\
& \mathrm{R}=\mathrm{CF}_{3}, \mathbf{3 d}
\end{aligned}
$$

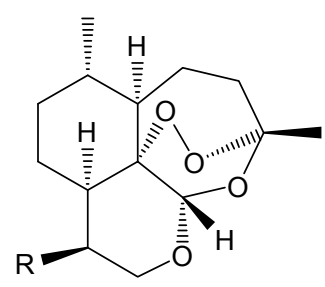

$\mathrm{R}=\mathrm{CH}_{3}, \mathbf{3 e}$

$\mathrm{R}=\left(\mathrm{CH}_{2}\right)_{3}, \mathrm{CH}_{3}, \mathbf{3 f}$

$\mathrm{R}=\left(\mathrm{CH}_{2}\right)_{3}, \mathrm{C}_{6} \mathrm{H}_{5}, \mathbf{3 g}$

$\mathrm{R}=\left(\mathrm{CH}_{2}\right)_{3}, p-\mathrm{ClC}_{6} \mathrm{H}_{5}, \mathbf{3 h}$

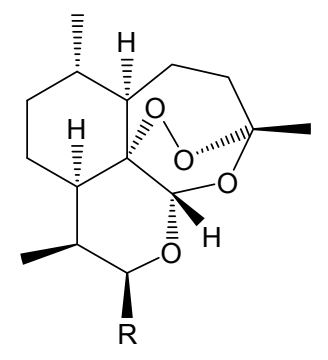

$\mathrm{R}=$ furan-2-yl, $\mathbf{3 i}$

$\mathrm{R}=$ indole-2-yl, $\mathbf{3 j}$

Figure 3 Some second-generation derivatives of artemisinin. 
<smiles>CC(O)[C@H](O)/C=C/[C@@]1(C)CC2CC(=O)[C@H](C)[C@@H]2OO1</smiles>

$4 a$

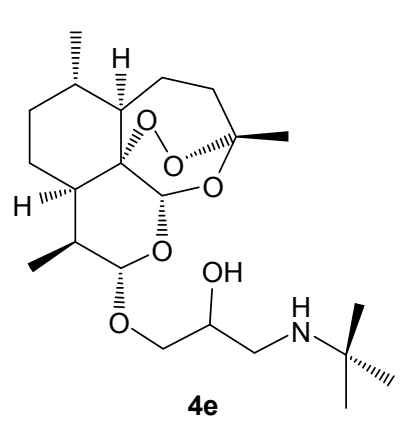<smiles>C[C@H]1C(=O)C[C@H]2C[C@@H]1OO[C@]2(C)/C=C\c1ccc(C(F)(F)F)cc1C(F)(F)F</smiles>

4b<smiles>C=C(C(=O)O)[C@H]1CC[C@@H](C)[C@H]2CCC(C)=C[C@H]12</smiles>

$4 c$<smiles>C=C1O[C@H]2CC[C@H](C)[C@@H]3CC[C@@]4(C)OO[C@@]23[C@@H](OC1=O)O4</smiles>

$4 d$<smiles>CC(C)(N)CNC(=O)C[C@H]1CC[C@]2(CC1)OO[C@@]1(CC3CC4CC(C3)C1C4)O2</smiles>

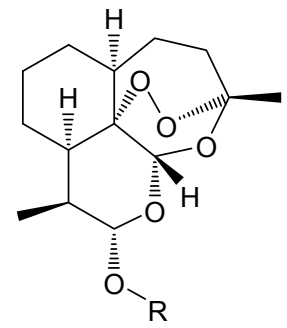

$4 f$

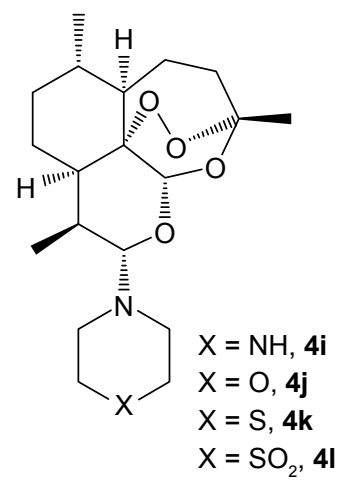

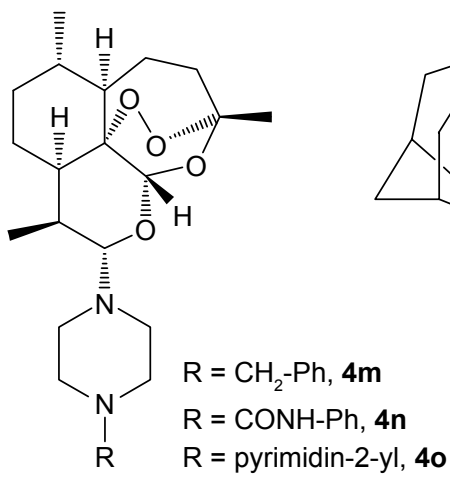

$\mathrm{R}=\mathrm{COC}_{6} \mathrm{H}_{4} \mathrm{C}_{6} \mathrm{H}_{5}, 4 \mathrm{~h}$

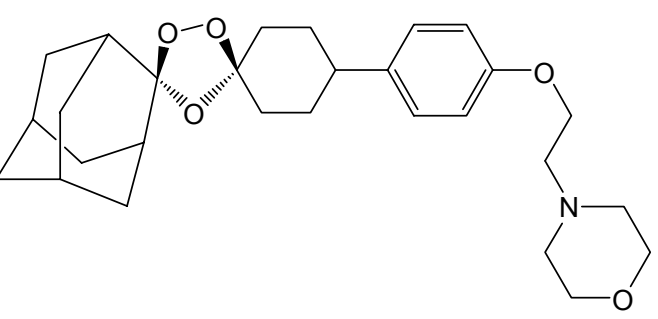

$4 p$

Figure 4 Some newer synthetic endoperoxides.

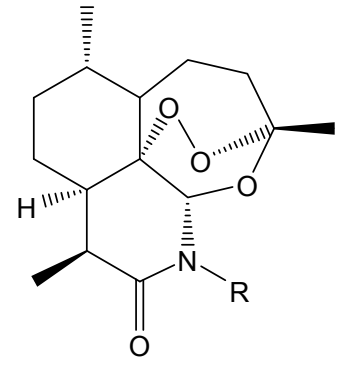<smiles>[R]C1([R])O[C@@H]2O[C@@]3(C)CC[C@H]4[C@@H](C)CC[C@H]([C@@H]1C)[C@]42OO3</smiles>

$\mathrm{R}=\mathrm{H}, \mathbf{5} \mathbf{a}$

$\mathrm{R}=\mathrm{NH}_{2}, \mathbf{5 b}$

$\mathrm{R}=\mathrm{OH}, \mathbf{5 c}$

$\mathrm{R}=\mathrm{CH}_{2} \mathrm{CH}_{2} \mathrm{OH}, \mathbf{5 d}$

$\mathrm{R}=\mathrm{CH}_{2} \mathrm{CHO}, 5 \mathbf{e}$

$\mathrm{R}=\mathrm{CH}_{2}$-(2-pyridyl), $\mathbf{5 f}$<smiles>C[C@@H]1CC[C@H]2C3CC[C@@]4(C)OO[C@]34[C@@H](OC(=C(F)F)[C@@H]2C)O1</smiles>

$5 i$

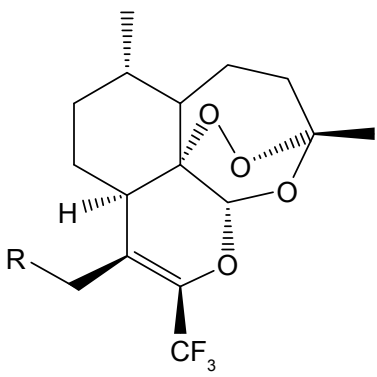

$5 j$

Figure $\mathbf{5}$ Newer aza and fluorinated endoperoxides. 
exhibits antimalarial, anticancer and antibacterial activities. ART is a naturally occurring 1,2,4-trioxane (Figure 6)containing lactone moiety in a tetracyclic structural skeleton. The endoperoxide bridge of 1,2,4-trioxane scaffold is believed to be the key pharmacophoric moiety of ART and related endoperoxides. ${ }^{24,28}$

1,2,4-Trioxanes $(\mathbf{7 a}-\mathbf{7 1})$ have been developed due to efforts aimed at creating peroxides with a simpler structure but still sufficiently active against malaria parasites including resistant strains. Increased effectiveness with 1,2,4-trioxanes leads to the understanding of fact that it is the minimum and optimum peroxide-based structural requirement for the desired antimalarial activity. Of all the 1,2,4-trioxane derivatives (Figure 7), the 2-adamantyl derivatives have been reported to be the most active compounds. ${ }^{28-31}$ They reduce parasitemia to an appreciable extent both in vitro and in vivo.

\section{I,2,4-Trioxolane-based}

1,2,4-Trioxolanes, the ozonides (10a-101), comprise another important class of organic peroxides. They exhibit excellent activity against malaria parasites, as do the structurally similar 1,2,4-trioxanes. Their activities are comparable to artesunate and artemether, both in vivo and in vitro, with improved pharmacokinetic (oral bioavailability, half-life, etc.) properties. $^{24,32,33}$ The structures of some potent 2-adamantyl derivatives of trioxolane are given in Figure 8.

\section{I,2,4,5-Tetraoxane-based}

3,6-Substituted derivatives of 1,2,4,5-tetraoxacyclohexane are known as 1,2,4,5-tetraoxanes. A group of 3,6-dispiro1,2,4,5-tetraoxanes $(\mathbf{9 a}-9 \mathbf{l})$ represented in Figure 9 have been reported to exhibit pronounced antimalarial activity against both CQ-sensitive and CQ-resistant strains of $P$. falciparum. The compounds with adamantyl substituents possess superior antimalarial effectiveness as compared to other compounds. The adamantyl substituent stabilizes the structure and improves the antimalarial activity. Some derivatives (9e) that contain polar sulfonamide groups at one end and a highly lipophilic adamantyl group at the other end also possess potent antimalarial activity. TDD E209 (9k) and RKA182 (9l) are known as next-generation tetraoxane-based antimalarial drugs. TDD E209 is said to be a single-dose cure agent in resistant malaria which is currently under preclinical phase of development. ${ }^{24,27,34-41}$

\section{Hybrid endoperoxides}

To overcome the problem of drug resistance, combination therapy has been used for years with limited success, and therefore, the concept of hybrid molecules has recently been introduced for the development of new drugs for treating resistant malaria. ${ }^{42,43}$ In hybrid (chimeric) molecules, two pharmacophores are covalently fused together to a single molecular entity. In such dual-drug therapy approach, drugs containing functional moieties from two different classes act independently at two distinct biological targets, which substantially improve the therapeutic response just similar to synergistic drug action. A single hybrid molecule with dual modes of action may therefore be beneficial for the treatment of resistant malaria with high antimalarial efficacy and resistance-preventing action. Alternatively, hybrid compounds may exhibit a unique mechanism of action which is likely to be different from the candidate drugs against which malaria parasites have developed resistance. ${ }^{43-49}$ In hybrid endoperoxides, also known as chimeric peroxides, mostly quinoline and peroxide moieties are the contributing pharmacophoric groups. Such hybrid analogs are attributed to have the property of resistance-preventing action with some important advantages such as improved pharmacokinetic properties

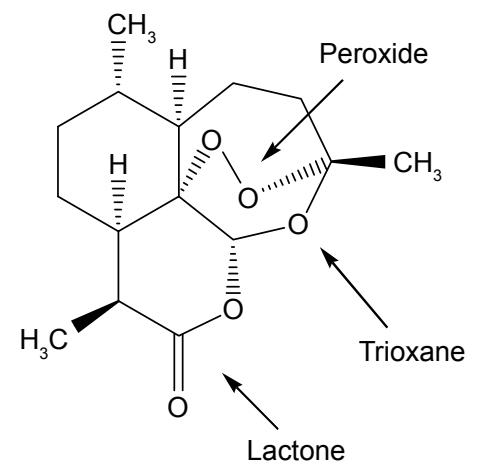

Natural endoperoxide (ART)tetracyclic endoperoxide

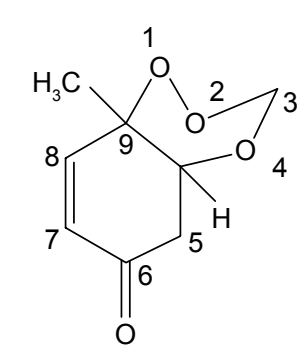

1,2,4-Trioxane moietybicyclic endoperoxide

Figure 6 1,2,4-Trioxane scaffold in artemisinin. 
<smiles>[R]C1OO[C@]2(C)C=CC(=O)C[C@]2(C)O1</smiles>

7a $\quad \mathrm{R}=\mathrm{H} /$ aryl $/$ heteroaryl

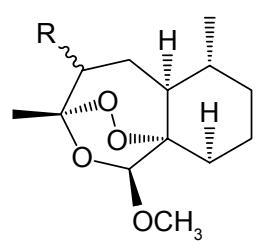

7b $\quad \mathrm{R}=$ alkyl
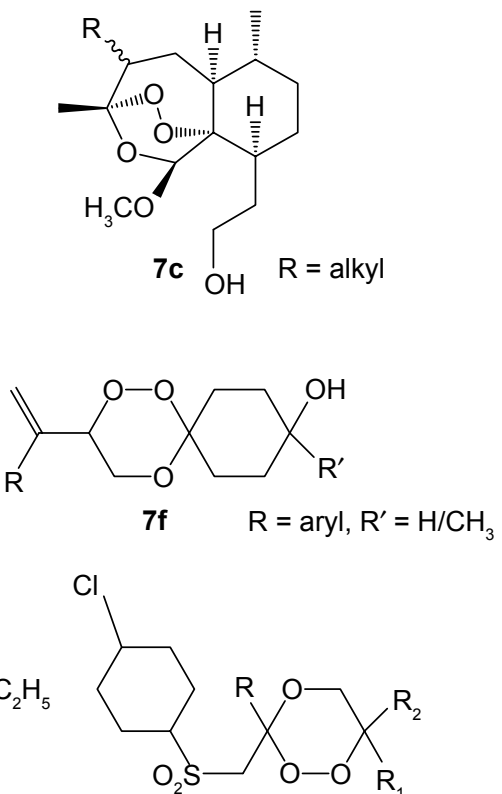

$7 \mathrm{i} \quad \mathrm{R}=$ aryl, $\mathrm{R}_{1}=\mathrm{R}_{2}=$ alkyl

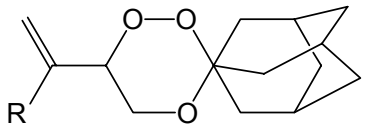

7j $\quad R=$ cycloalkyl/ary

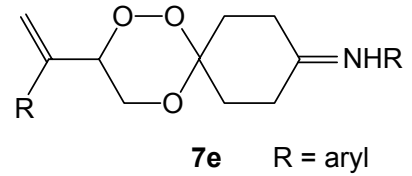

7e $\quad \mathrm{R}=$ aryl

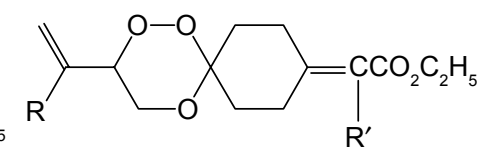

7h $\mathrm{R}=$ aryl, $\mathrm{R}^{\prime}=\mathrm{H} / \mathrm{CH}_{3}$

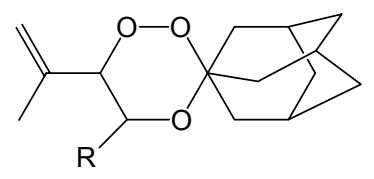

$\mathrm{R}=\mathrm{CH}_{3} I$

7k cyclopropyl/n-Pr

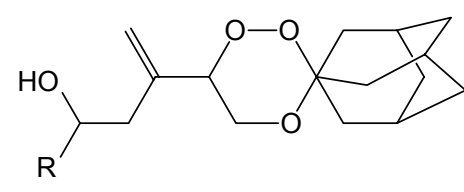

7I $\mathrm{R}=$ aryl

Figure 7 Some 1,2,4-trioxane-based antimalarials.

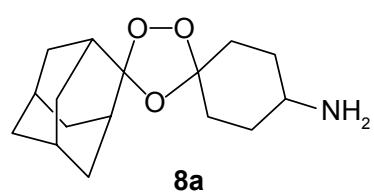

$8 a$

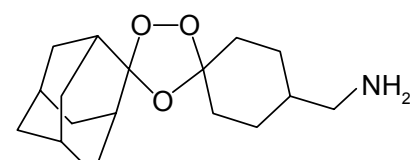

$8 b$

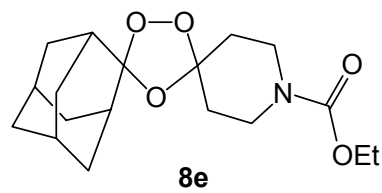

8d $\quad \mathrm{CO}_{2} \mathrm{H}$

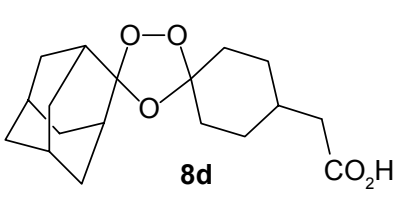

$8 \mathrm{e}$

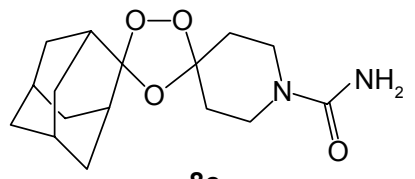

$8 c$
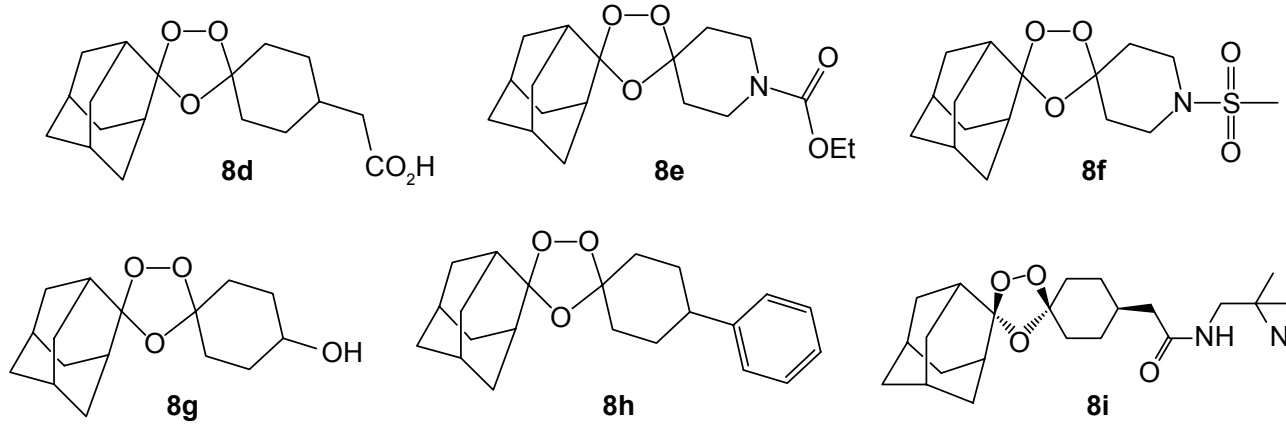

$8 \mathrm{~h}$

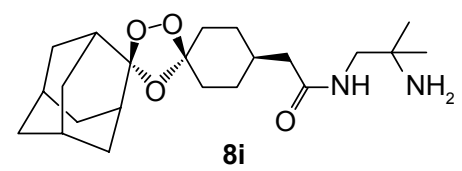

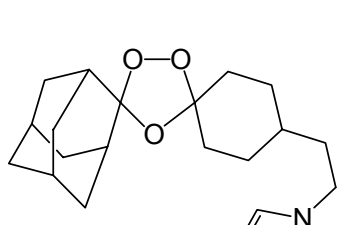

8j<smiles></smiles>

8k

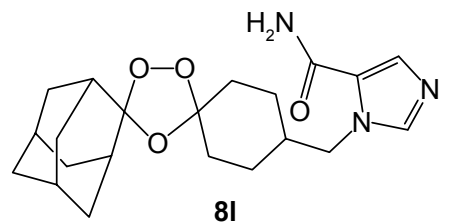

Figure 8 Some 1,2,4-trioxolane-based antimalarials. 


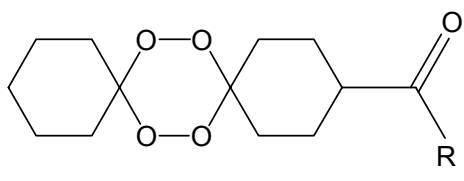

$\mathrm{R}=\mathrm{NHCH}_{2} \mathrm{CH}_{2} \mathrm{~N}\left(\mathrm{CH}_{3}\right)_{2}$

$9 a$

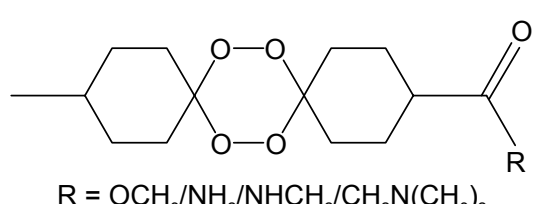

9d

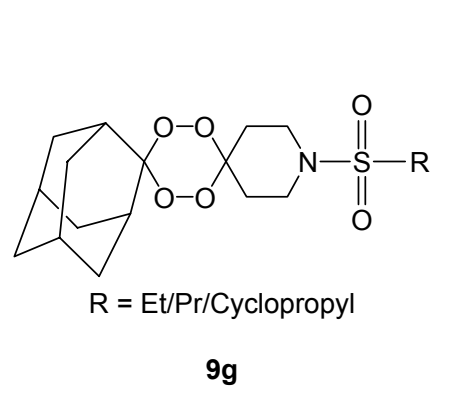

$9 \mathrm{~g}$

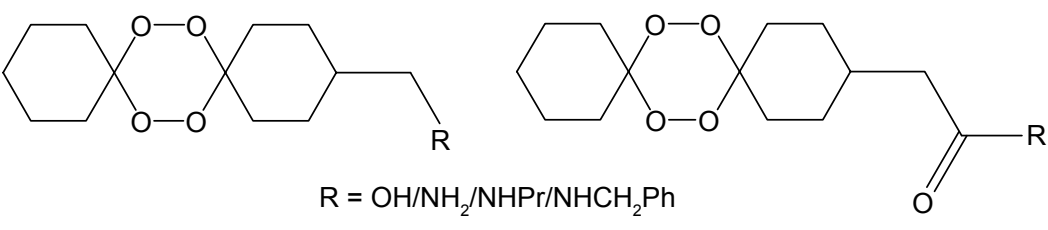

$9 b$

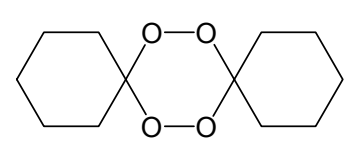

$9 e$

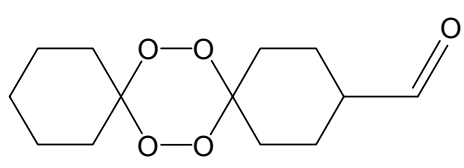

$9 f$

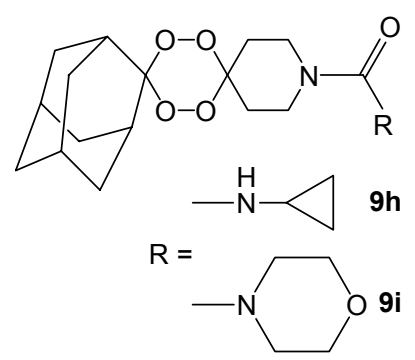<smiles></smiles>

9j
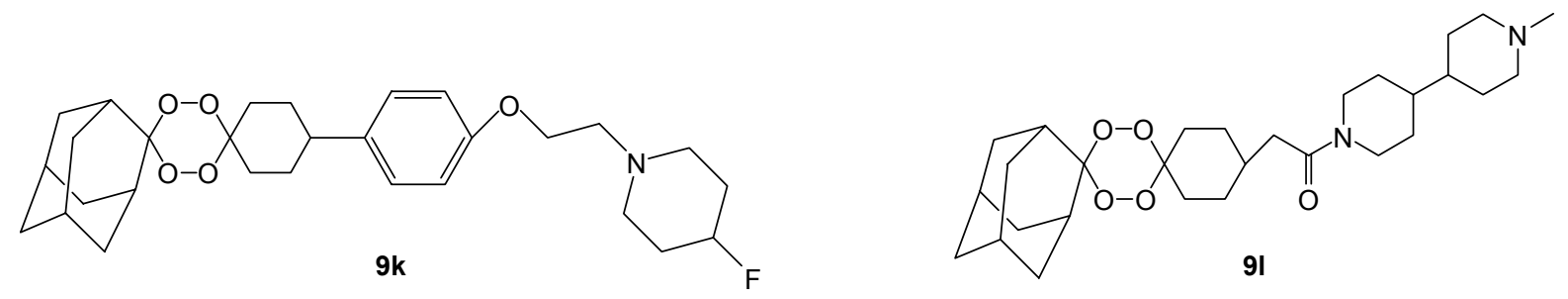

Figure 9 Some 1,2,3,4-tetraoxane-based antimalarial agents.

over traditional drugs such as QN, CQ, MQ and ART, and trioxanes, ozonides and tetraoxanes. ${ }^{24,50}$ Moreover, this novel strategy of delivering combination chemotherapy through a single chemical entity remains not only therapeutically efficacious but also cost-effective which ultimately reduces the overall drug pressure of the treatment. Endoperoxide-based hybrid compounds therefore represent an attractive alternative approach to ACTs.

\section{ART hybrids}

Some ART endoperoxide-based hybrid compounds are ART-QN (10a), ART-MQ (10b), ART-9-aminoacridine (10c), ART-vinylsulfones (10d) and ART-4-AQs (10e). They possess significantly higher activity than ART and QN or MQ or CQ. ${ }^{24,51-53}$ Figure 10 depicts the structure of some ART-based hybrid compounds.

\section{I,2,4-Trioxane hybrids}

Based on the "covalent bitherapy" approach, hybrids of 1,2,4-trioxane and $\mathrm{AQ}$, named trioxaquines, have been developed. A trioxaquine molecule is constituted as follows: quinoline-linker-trioxane. The 1,2,4-trioxane entity of trioxaquine is responsible for the activity of ART, whereas the AQ entity is necessary for the accumulation (pharmacokinetics) of the drug within the parasite. The antimalarial activities of trioxaquines (12a-12h) depicted in Figure 11 are significantly higher than the activity of each of the individual fragments, indicating a synergistic effect of the trioxaquine and AQ components. ${ }^{24,54-56}$

Compounds 11a and 11c-11g are 1,2,4-trioxaquine4-AQ hybrids, compound $\mathbf{1 1 b}$ is 1,2,4-trioxaquine-8-AQ hybrid and compound $\mathbf{1 1 h}$ is the 1,2,4-trioxaquineferroquine hybrid. Some of these hybrid analogs show excellent oral effectiveness, but some molecules suffer from limitations such as poor stability and poor solubility. Trioxaquines are regarded as first-generation endoperoxidebased hybrids. ${ }^{24,56}$ Recently, novel coumarin-trioxane hybrids (11i) have been reported to possess good antimalarial activity both in vitro and in vivo against CQ-sensitive strain of P. falciparum. ${ }^{57}$ Steroidal (pregnane-based, C-21 


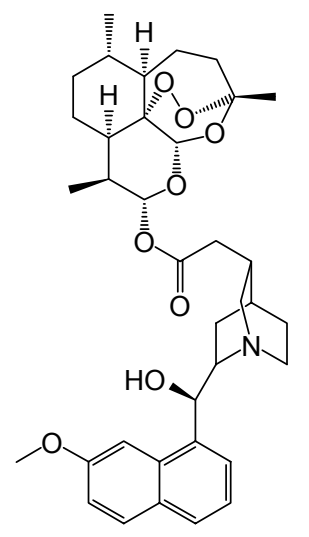

$10 \mathrm{a}$

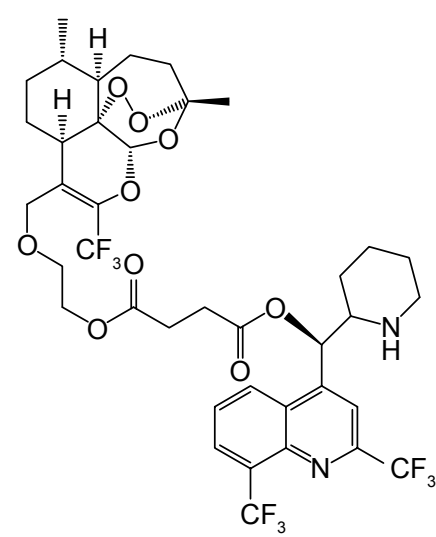

10b
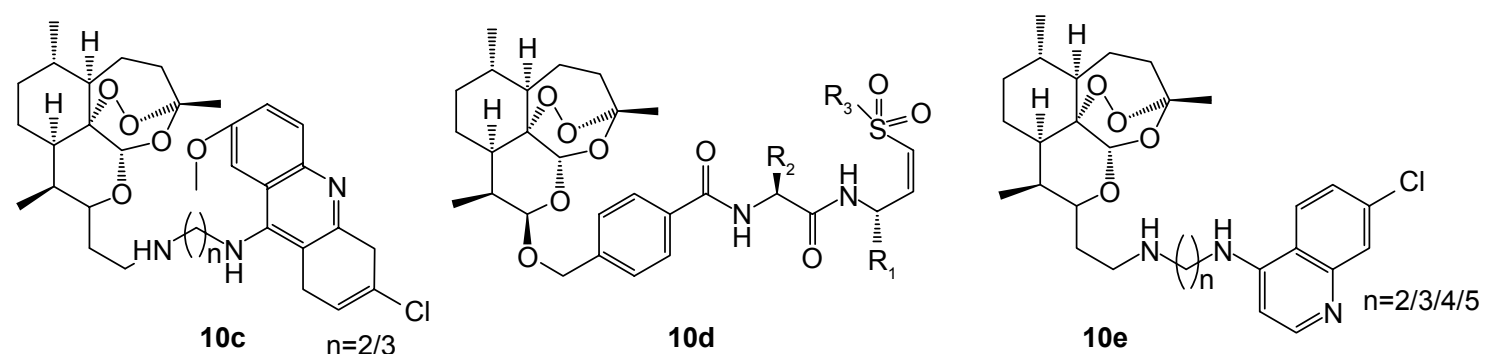

Figure 10 Artemisinin hybrids.<smiles>CC(C)C1=CC[C@H]2OC3(CCC(NCCNc4ccnc5cc(Cl)ccc45)CC3)OOC2(C)C1</smiles>

11a<smiles>Clc1ccc2c(NC=NC3CCC4(CC3)OOC3CCC=CC3O4)ccnc2c1</smiles>

11d

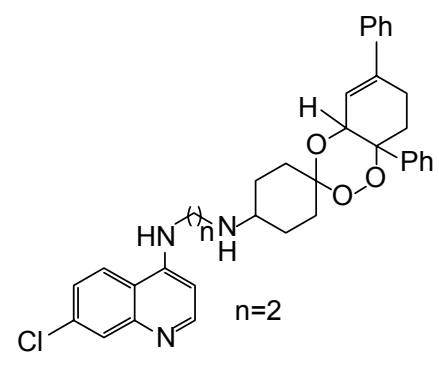

$11 \mathrm{~g}$<smiles></smiles>

11b<smiles>C=C(CC)C1COC2(CCC(NCNc3ccnc4cc(Cl)ccc34)CC2)OO1</smiles>

$11 e$

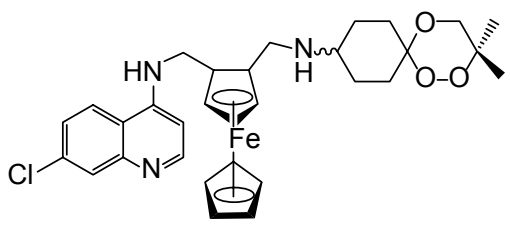

$11 \mathrm{~h}$<smiles>Clc1ccc2c(NCNC3CCC4(CC3)OOC3(c5ccccc5)CC(c5ccccc5)=CC3O4)ccnc2c1</smiles>

$11 \mathrm{c}$<smiles>CC1(C)COC2(CCC(NC3CCC(Nc4ccnc5cc(Cl)ccc45)CC3)CC2)OO1</smiles>

$11 f$<smiles>[R][R]=[R]=[SiH]=[W]</smiles>

$11 \mathrm{i}$

Figure II Trioxaquines and trioxane-coumarin hybrids. 

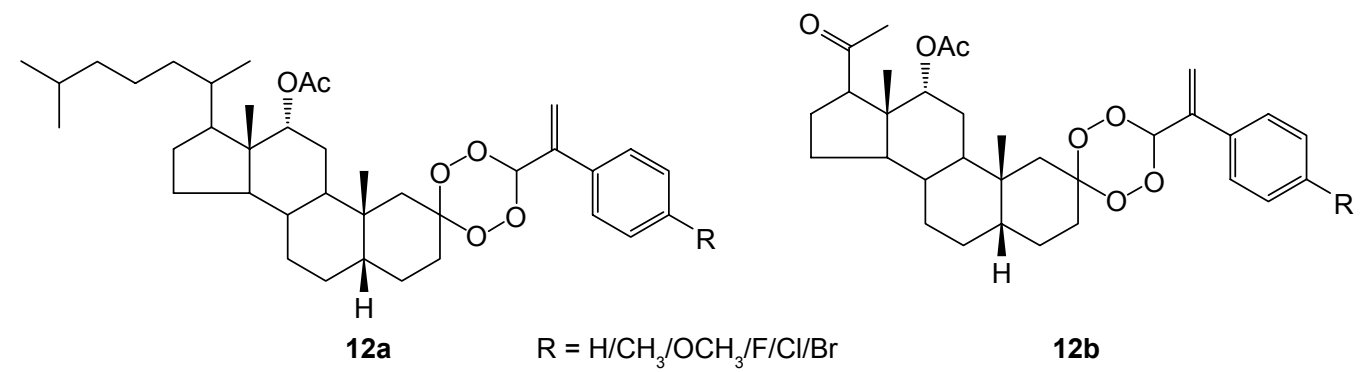

$12 b$

Figure 12 Some steroidal I,2,4-trioxane hybrids.

steroid) 1,2,4-trioxane hybrids (Figure 12) also exhibit good antimalarial activity with high suppression rate of parasitemia. $^{24}$

\section{I,2,4-Trioxolane hybrids}

In recent literature, second-generation hybrids of endoperoxide, called trioxalaquines, have been reported. In trioxalaquines, the quinoline moiety, mostly $4-\mathrm{AQ}$, is conjugated with a 1,2,4-trioxolane moiety through a functional linker (trioxalaquines $=$ quinoline-linker-trioxolane). These hybrid analogs also exhibit potent antimalarial activity against gametocytes. Trioxalaquine hybrids are adamantylated derivatives of 4-AQ (13a, 13b, 13e) or 8-AQ (13c) or aminoacridine (13d) moiety and simply nonadmantylated vinylsulfonylurea conjugates (15f) of 1,2,4-trioxolane (Figure 13).24,50,58

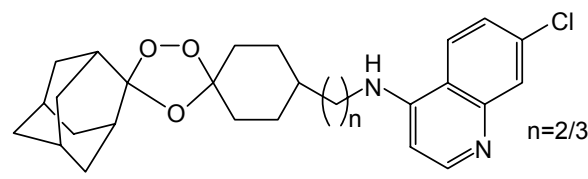

13a
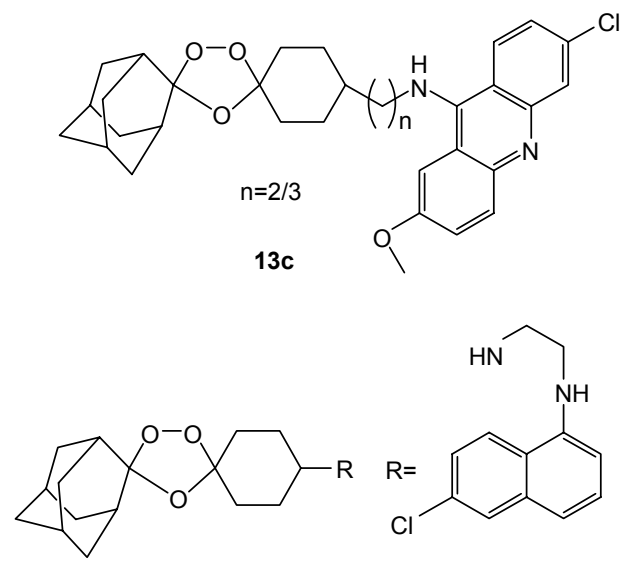

$13 e$

\section{I,2,4,5-Tetraoxane hybrids}

1,2,4,5-Tetraoxane hybrids (Figure 14) include tertraoxane-4-AQ, known as tetraoxaquines $(\mathbf{1 4 a}, \mathbf{1 4 b})$, tetraoxane-vinylsulfone analogs (14c) and adamantylated tetraoxane-vinylsulfone analogs (14d). They are as active as ART or MQ against the $P$. falciparum strain and possess higher activity than CQ against CQ-resistant strains. ${ }^{24,50,59}$

Moreover, some complex molecules mixed with steroidal tetraoxanes have been developed (Figure 15) which exhibit impressive in vitro and in vivo antimalarial activity. ${ }^{24}$

\section{Pharmacodynamics of endoperoxide antimalarials}

\section{General aspects}

The lifecycle of Plasmodium parasite is a complex biological phenomenon which comprises three major stages: mosquito

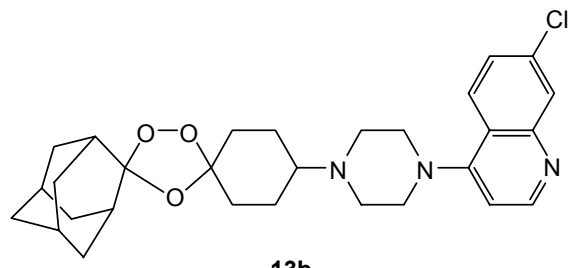

$13 b$
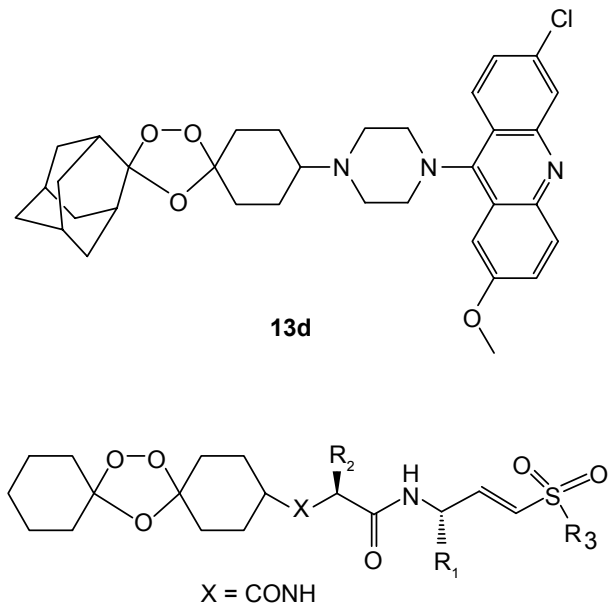

$13 f$

Figure 13 Trioxalaquines and trioxolane-vinylsulfone hybrids. 


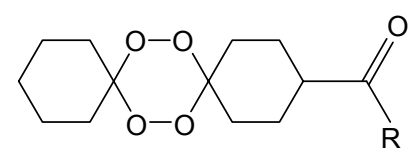

$14 a$

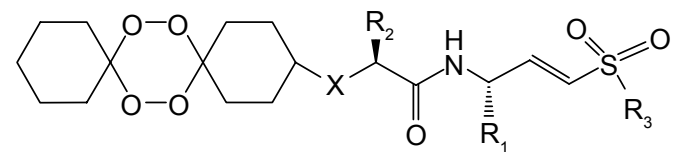

$\mathrm{X}=\mathrm{CONH}$

$14 \mathrm{c}$

Figure 14 Tetraoxaquines and related hybrid analogs.

(sporogony) stage, human liver (tissue schizogony) stage and human blood (erythrocytic schizogony) stage. During blood stage, within the erythrocytes (red blood cells [RBCs]), the parasite develops through several asexual stages such as rings, trophozoites, early schizonts and mature schizonts (Figure 16). At this stage, the malaria parasite uses host hemoglobin $(\mathrm{Hb})$ as its primary food source. In $P$. falciparum infection, about $60 \%-70 \%$ of host $\mathrm{Hb}$ is degraded by the parasite. ${ }^{60-63}$

This catabolic process of $\mathrm{Hb}$ degradation is believed to occur in a specialized acidic ( $\mathrm{pH}$ 5.0-5.4) metabolic organelle within the parasitized RBC, known as food vacuole (FV). The details of $\mathrm{Hb}$ digestion in parasites which are important to understand the biochemical mechanism of action of ARTbased drugs are represented in Figure 17.
Literature reveal that heme polymerase enzyme, $\mathrm{Hb}$ degrading protease enzymes (plasmepsins and falcipains) and heme (heme/Ferriprotoporphyrin) are some potential enzymatic/nonenzymatic targets involved in the antimalarial action of major drugs including QN, CQ and ARTs. It has been proposed that hematin, upon reduction to heme, is the source of ferrous iron [Fe(II)] that is responsible for bioactivation of the endoperoxide bridge of ART to cytotoxic carbon radical species which destroy Plasmodium parasites. It is therefore noteworthy that generation of heme during HB digestion process is attributed to be the fundamental biochemical basis of rational drug design of newer antimalarial drugs. However, a majority of antimalarial drugs are weak bases which accumulate in the acidic FV of parasites by $\mathrm{pH}$-trapping (or ion-trapping) mechanism. Therefore,<smiles>[R]c1ccc(C(=O)C2OOC3(CC[C@H]4CCC5C6CC[C@H](C(C)=O)[C@]6(C)[C@H](OC(C)=O)C[C@H]5[C@]4(C)C3)OO2)cc1</smiles>

$15 a$

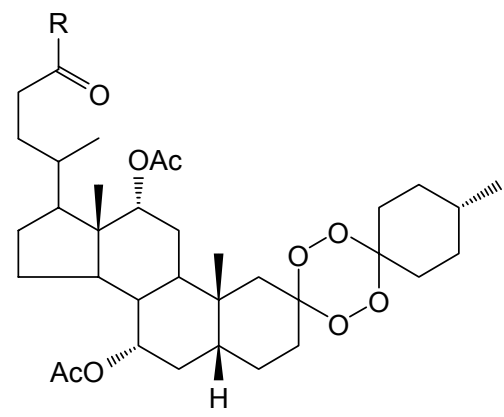

15c $\mathrm{R}=\mathrm{OH}, \mathrm{NH}_{2}, \mathrm{NHPr}^{\mathrm{n}}, \mathrm{NHPh}$<smiles>[R]c1ccc(C(=O)C2OOC3(CC[C@H]4CCC5C6CC[C@H](C(C)CCCC(C)C)[C@]6(C)[C@H](OC(C)=O)C[C@H]5[C@]4(C)C3)OO2)cc1</smiles>

$\mathrm{R}=\mathrm{OH}, \mathrm{NH}_{2}, \mathrm{NHPr}^{\mathrm{n}}, \mathrm{NHPh}$

$15 b$

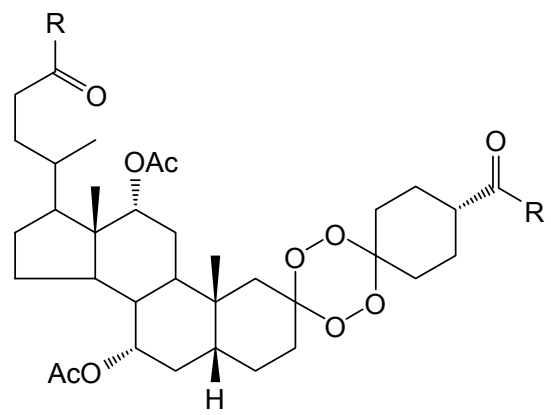

$15 d$

$\mathrm{R}=\mathrm{NHPr}{ }^{\mathrm{n}}, \mathrm{NHPh}$

Figure 15 Some 1,2,3,4-tetraoxane steroids. 


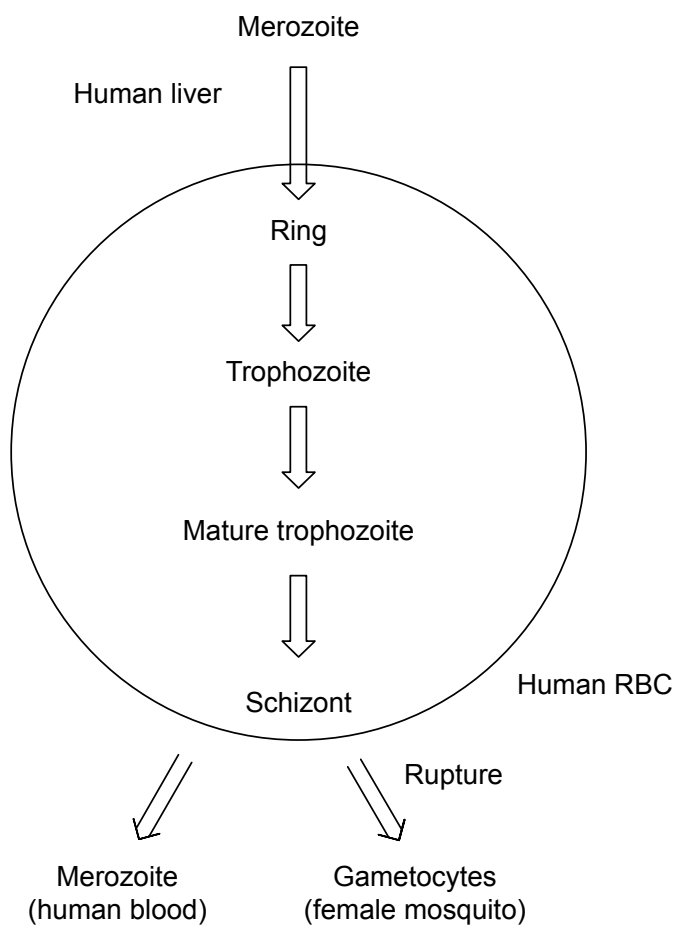

Figure 16 Blood stages of malaria parasites. Abbreviation: $R B C$, red blood cell. basicity (pKa) of drug molecules and cytoplasmic/vacuolar $\mathrm{pH}$ are other important considerations to achieve targetspecific drug action wherever desired at either cellular or molecular level in malaria parasites. ${ }^{62,63}$

\section{Mechanism of action: 1,2,4-trioxanes and related endoperoxides}

ART including semisynthetic derivatives and related endoperoxide antimalarials and derivatives exhibit high efficacy against the blood stages of Plasmodium, including the youngest ring forms, and mature trophozoites with activity to some extent against various forms of gametocytes in the blood. For instance, the in vitro activity profile of newer synthetic endoperoxides, arterolane (OZ277) and artefenomel (OZ439), has confirmed their efficacy as blood schizontocide against all blood stages of ART-resistant P. falciparum without effect on liver stages. The endoperoxide bridge of 1,2,4-trioxanes and related endoperoxides (natural/synthetic) appears to be essential for the antimalarial activity. An ART derivative lacking the endoperoxide bridge (deoxyartemisinin) is devoid of antimalarial activity. The role

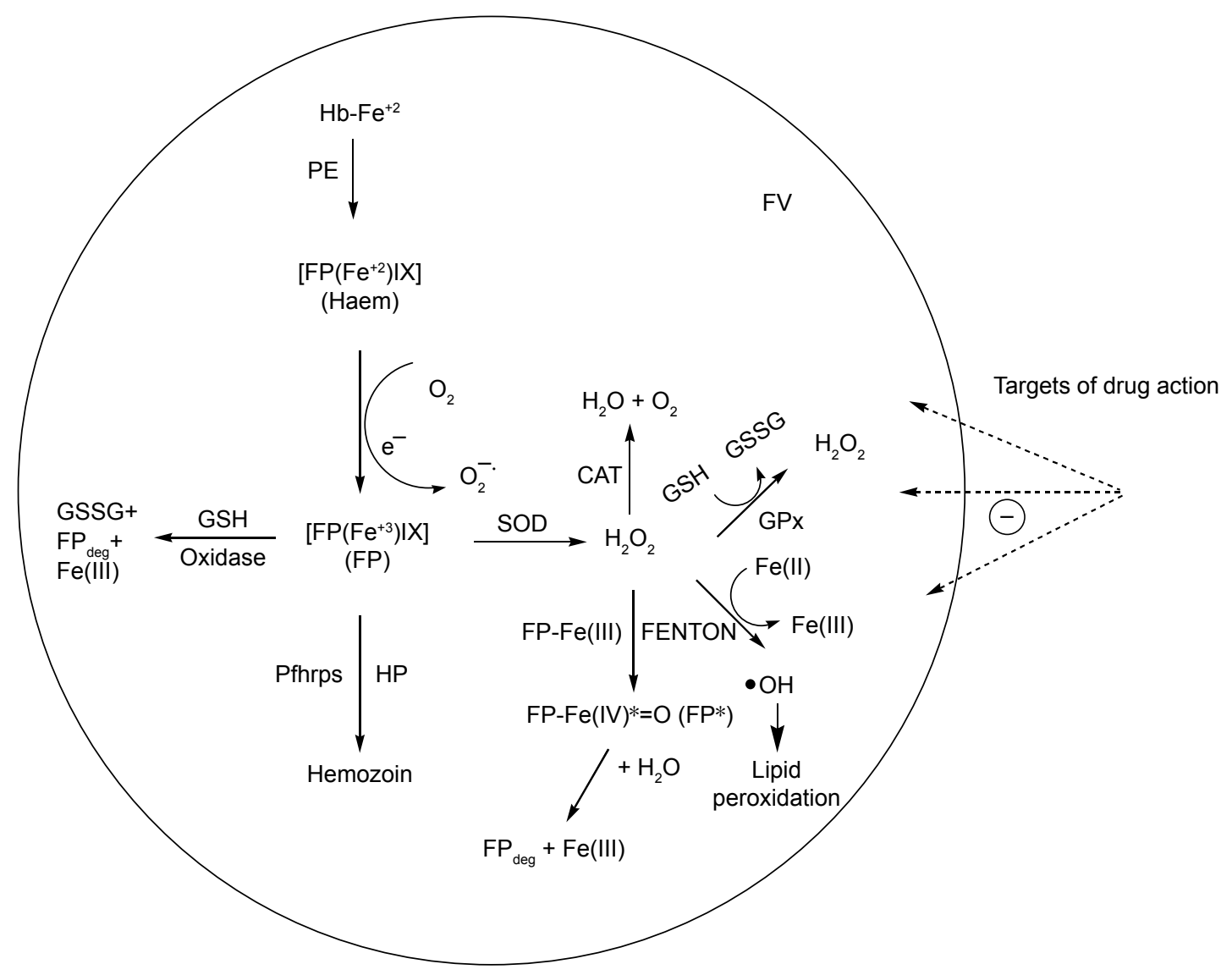

Figure 17 Hemoglobin degradation mechanism and enzymatic/nonenzymatic targets of antimalarial drug action.

Abbreviations: FV, food vacuole; FP, ferriprotoporphyrin; PE, protease enzymes; FP ${ }_{\text {deg }}$ FP degraded; Pfhrps, Plasmodium falciparum histidine-rich proteins; HP, heme polymerase; SOD, superoxide dismutase; CAT, catalase; GSH, reduced glutathione; GSSG, oxidized glutathione; GPx, glutathione peroxidase. 
of endoperoxide ring is depicted as follows. Endoperoxide ring is reductively activated on interaction with heme [Fe(II)] released during parasite $\mathrm{Hb}$ digestion, which leads to homolytic cleavage of the peroxide $(\mathrm{O}-\mathrm{O})$ bond of trioxanes generating stable cytotoxic species, called carbon-centered free radicals (carbocations). These reactive species cause membrane damage, alkylation, oxidation of proteins and fats, inhibition of protein and nucleic acid synthesis and interaction with cytochrome oxidase and the glutamine transport system in parasites. ${ }^{13,64-67}$ Iron (II)-mediated cleavage of trioxane endoperoxide bridge was first proposed by Zhang et al. ${ }^{68}$ A plausible mechanism of trioxane endoperoxide (ART) bond cleavage and consequent lipid peroxidation in parasites is outlined in Figure 18. This mechanism depicts a typical oxidative reaction that occurs in parasite cell damage under oxidative stress (OS) induced by reactive oxygen species such as the hydroxyl radicals and the superoxide anion derived from several carbon radical intermediates. Cumming et $\mathrm{al}^{65}$ studied that interaction of lipid-solubilized heme with ART followed by $\mathrm{Fe}(\mathrm{II})$-mediated generation of oxyl and carbon radicals (bioactivation) places these reactive intermediates in the vicinity of target allylic hydrogens of unsaturated lipid bilayers. Hydrogen abstraction and allylic carbon radical formation with subsequent reaction oxygen gain result ultimately in the formation of lipid hydroperoxides. It has however been reported that the antimalarial activity is dependent not merely on peroxide bond cleavage but also on the ability of reactive intermediates to alkylate heme or other proximal targets. It has been suggested that the damage caused to the parasite's vacuolar membrane is due to Fe(II)mediated bioactivation of endoperoxide ring and resulting OS. It is believed that sometimes, these radical species directly target heme and alkylate heme molecule (parasite proteins). This alkylation mechanism is another key target of endoperoxide-based antimalarial drugs. ${ }^{32,64-69}$

$\mathrm{Fe}$ (II) at both cellular and molecular levels is involved in bioactivation of peroxide molecules. This involves two different pathways of endoperoxide cleavage (Figure 19) which leads to formation of oxyl radicals followed by carboncentered radicals that ultimately produce a high-valent $\mathrm{Fe}(\mathrm{IV}) \mathrm{O}$ species (from the pathway where formation of $\mathrm{C} 4$ radical takes place by a 1,5-hydrogen atom abstraction mechanism) which has been proposed to oxidatively damage cellular macromolecules. However, heme iron [Fe(II)] plays a crucial role in bioactivation of endoperoxides resulting in reactive oxygen metabolite-induced cytotoxicity. ${ }^{34,64,70}$
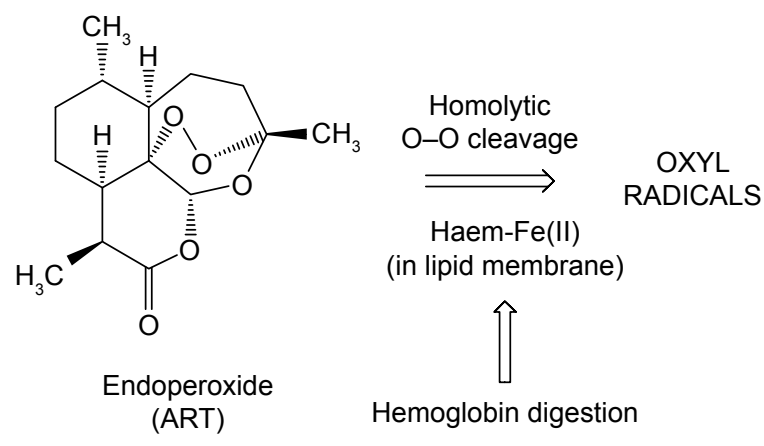

Parasite death

Oxidative damage to proteins, enzymes, receptors, etc

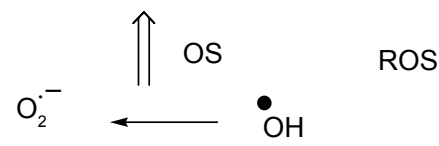

Superoxide Hydroxyl radical

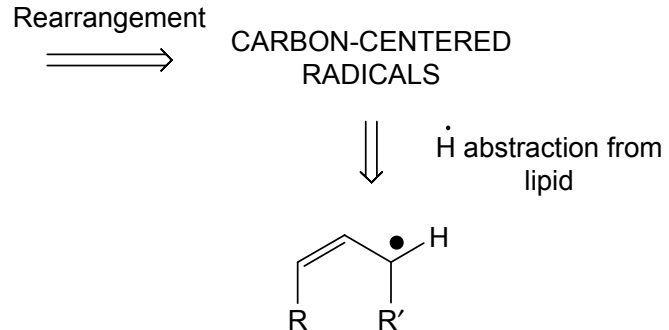

Allylic C-radical

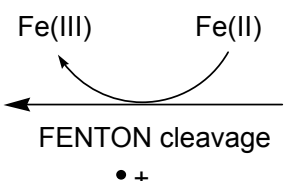<smiles>[R]C=C[C@@H]([R])OO</smiles>

Figure 18 Mechanism of action of endoperoxide antimalarials. Abbreviation: ART, artemisinin. 


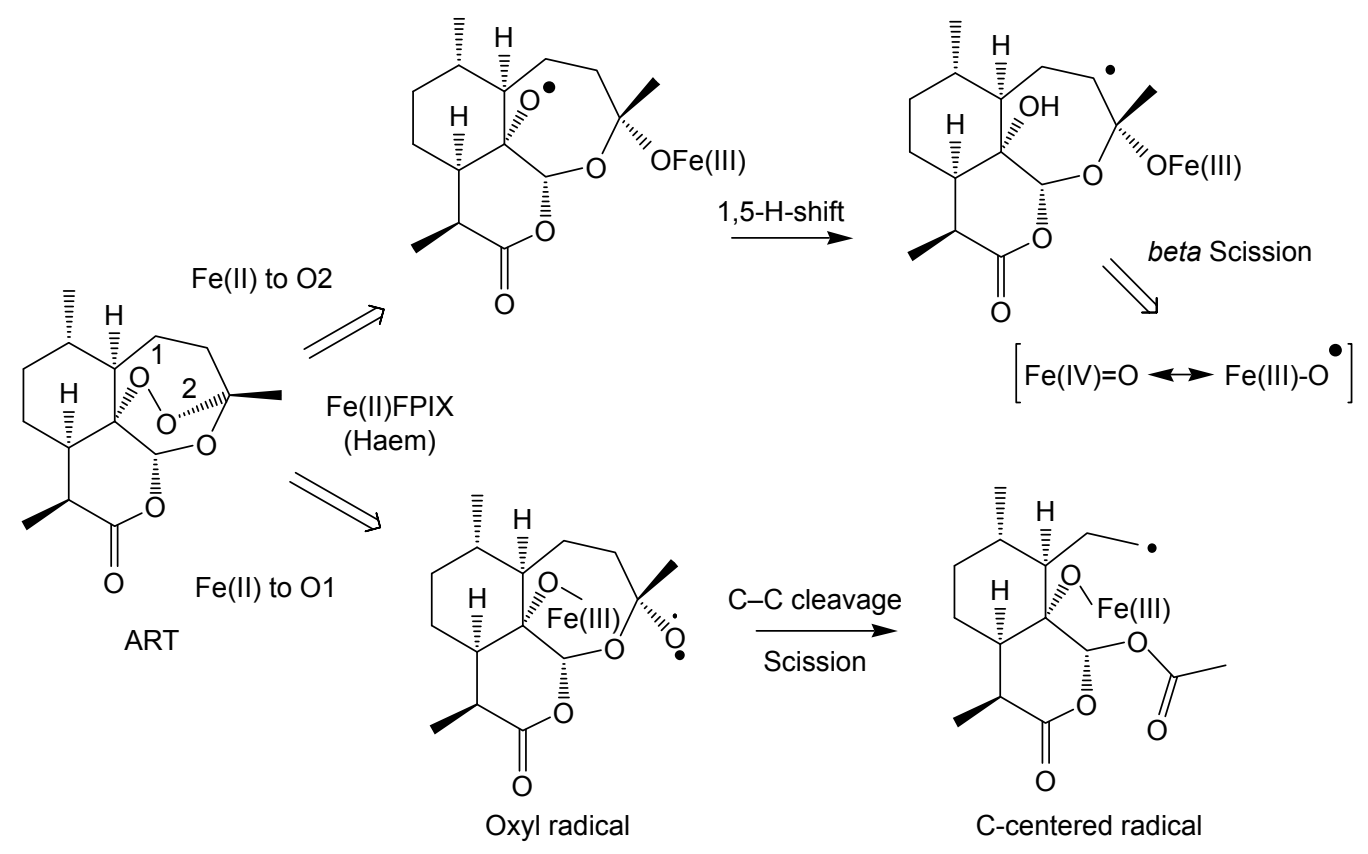

Figure 19 Heme activation reactions - generation of free radicals.

\section{Conclusion}

Endoperoxide antimalarials represent a huge number of antimalarial agents having a wide structural diversity with desired antimalarial effectiveness. In endoperoxide scaffolds, the 1,2,4-trioxane ring system (lacking lactone ring) acts as the key pharmacophoric moiety, which is therefore a fundamental structural requirement toward achieving desired antimalarial (biodynamic) potential with optimal pharmacokinetic properties. This is also an important biological rationale behind antimalarial activities of a wide array of endoperoxide analogs described herein. In this context, endoperoxide scaffolds (1,2,4-trioxane-, 1,2,4-trioxolane- and 1,2,4,5-teraoxanebased) and their chemical analogs including chimeric (hybrid) molecules remain as a rich source of newer lead molecules for the development of potent antimalarial drug candidates. Since the presence of peroxide system alone is not sufficient for the antimalarial activity of such analogs, this developmental strategy would require molecular design and in silico optimization studies in order to achieve potent antimalarial molecules (active against resistant malaria) without affecting target specificity (efficacy) and host toxicity.

\section{Acknowledgment}

M Rudrapal is thankful to UGC, New Delhi, India, for the financial support in the form of fellowship (JRF).

\section{Disclosure}

The authors report no conflicts of interest in this work.

\section{References}

1. WHO. World Malaria Report. Geneva: WHO; 2015.

2. Roy S, Chetia D, Rudrapal M, Prakash A. Synthesis and antimalarial activity study of some new Mannich bases of 7-chloro-4-aminoquinoline. Med Chem. 2013;9(3):379-383.

3. Rudrapal M, Chetia D, Prakash A. Synthesis, antimalarial and antibacterial activity evaluation of some new 4-aminoquonoline derivatives. Med Chem Res. 2013;22(8):3703-3711.

4. Warrell DA. Cerebral malaria. Schweiz Med Wochenschr. 1992; 122(23):879-886.

5. Ridley RJ. Medical need, scientific opportunity and the drive for antimalarial drugs. Nature. 2002;415:686-693.

6. Farooq U, Mahajan RC. Drug resistance in malaria. J Vector Borne Dis. 2004;41(3-4):45-53.

7. Winstanley PA, Ward SA, Snow RW. Clinical status and implications of antimalarial drug resistance. Microbes Infect. 2002;4(2): $157-164$.

8. Bray PG, Ward SA, O'Neill PM. Quinolines and artemisinin: chemistry, biology and history. Curr Top Microbiol Immunol. 2005;295:3-38.

9. Robert A, Benoit-Vical F, Dechy-Cabaret O, Meunier B. From classical antimalarial drugs to new compounds based on the mechanism of action of artemisinin. Pure Appl Chem. 2001;73(7):1173-1180.

10. Aguiar AC, Rocha EM, Souza NB, França TC, Krettli AU. New approaches in antimalarial drug discovery and development - a review. Mem Inst Oswaldo Cruz. 2012;107(7):831-845.

11. Luo XD, Shen CC. The chemistry, pharmacology, and clinical applications of qinghaosu (artemisinin) and its derivatives. Med Res Rev. 1987;7(1):29-52.

12. Balint GA. Artemisinin and its derivatives: an important new class of antimalarial agents. Pharmacol Ther. 2001;90(2-3):261-265.

13. Meshnick SR. Artemisinin: mechanisms of action, resistance and toxicity. Int J Parasitol. 2002;32(13):1655-1660.

14. Liu Y, Cui K, Lu W, et al. Synthesis and antimalarial activity of novel dihydro-artemisinin derivatives. Molecules. 2011;16(6):4527-4538.

15. Kyle DE, Teja-Isavadharm P, Li Q, Leo K. Pharmacokinetics and pharmacodynamics of qinghaosu derivatives: how do they impact on the choice of drug and the dosage regimens? Med Trop (Mars). 1998; 58(3 Suppl):38-44. 
16. White NJ. Clinical pharmacokinetics and pharmacodynamics of artemisinin and derivatives. Trans R Soc Trop Med Hyg. 1994;88(Suppl 1): S41-S43.

17. Bethel D, Se Y, Lon C, et al. Artesunate dose escalation for the treatment of uncomplicated malaria in a region of reported artemisinin resistance: a randomized clinical trial. PLoS One. 2011;6(5):e19283.

18. White NJ. Assessment of the pharmacodynamic properties of antimalarial drugs in vivo. Antimicrob Agents Chemother. 1997;41(7):1413-1422.

19. Garner P, Graves PM. The benefits of artemisinin combination therapy for malaria extend beyond the individual patient. PLoS Med. 2005;2(4):e105.

20. A Study by the Tracking Resistance to Artemisinin Collaboration (TRAC) (TRACII). UK: University of Oxford; [updated December 2, 2015] Available from: https://clinicaltrials.gov/ct2/show/NCT02453308. Accessed September 8, 2016.

21. Park BK, O’Neill PM, Maggs JL, Pirmohamed M. Safety assessment of peroxide antimalarials: clinical and chemical perspectives. Br J Clin Pharmacol. 1998;46(6):521-529.

22. Tang Y, Dong Y, Vennerstrom JL. Synthetic peroxides as antimalarials. Med Res Rev. 2004;24(4):425-448.

23. Cumming JN, Wang D, Park SB, Shapiro TA, Posner GH. Design, synthesis, derivatization, and structure-activity relationships of simplified, tricyclic, 1,2,4-trioxane alcohol analogues of the antimalarial artemisinin. J Med Chem. 1998;41(6):952-964.

24. Opsenica DM, Šolaja BA. Antimalarial peroxides (review). J Serb Chem Soc. 2009;74(11):1155-1187.

25. Medicines for Malaria Venture (MMV). Peroxide potential for malaria. Geneva: MMV. Available from: http:/www.mmv.org/sites/default/ files/uploads/docs/publications/. Accessed September 12, 2016.

26. Medicines for Malaria Venture (MMV). MMV Project of the Year award - 2006. Geneva: MMV. Available from: http://www.mmv.org/ research-development/project-year-award/mmv-project-year-award2006. Accessed September 15, 2016.

27. Medicines for Malaria Venture (MMV). MMV annual report 2015. Geneva: MMV. Available from: http://www.mmv.org/newsroom/ publications/annual-report-2015. Accessed September 20, 2016.

28. Poonsakdi P. Development of artemisinin and its structurally simplified trioxane derivatives as antimalarial drugs. Acta Trop. 2004;89(3) 329-342.

29. Ramirez AP, Thomas AM, Woerpel KA. Preparation of bicyclic 1,2,4-trioxanes from $\gamma, \delta$-unsaturated ketones. Org Lett. 2009;11(3): 507-510.

30. Rubush DM, Morges MA, Rose BJ, Thamm DH, Rovis T. An asymmetric synthesis of 1,2,4-trioxane anticancer agents via desymmetrization of peroxyquinols through a Brønsted acid catalysis cascade. J Am Chem Soc. 2012;134(33):13554-13557.

31. Mott BT, Tripathi A, Siegler MA, Moore CD, Sullivan DJ, Posner GH. Synthesis and antimalarial efficacy of two-carbon-linked, artemisininderived trioxane dimers in combination with known antimalarial drugs. J Med Chem. 2013;56(6):2630-2641.

32. Wang X, Creek DJ, Schiaffo CE, et al. Spiroadamantyl 1,2,4-trioxolane, 1,2,4-trioxane, and 1,2,4-trioxepane pairs: relationship between peroxide bond iron(II) reactivity, heme alkylation efficiency, and antimalarial activity. Bioorg Med Chem Lett. 2009;19(16):4542-4545.

33. Dong Y, Chollet J, Matile H, et al. Spiro and dispiro-1,2,4-trioxolanes as antimalarial peroxides: charting a workable structure-activity relationship using simple prototypes. J Med Chem. 2005;48(5):4953-4961.

34. Vennerstrom JL, Fu HN, Ellis WY, et al. Dispiro-1,2,4,5-tetraoxanes: a new class of antimalarial peroxides. J Med Chem. 1992;35(16): 3023-3027.

35. Vennerstrom JL, Dong Y, Andersen SL, et al. Synthesis and antimalarial activity of sixteen dispiro-1,2,4,5-tetraoxanes: alkyl-substituted 7,8,15,16-tetraoxadispiro[5.2.5.2] hexadecanes. J Med Chem. 2000; 43(14):2753-2758.

36. Amewu RK, Chadwick J, Hussain A, et al. Synthesis and evaluation of the antimalarial, anticancer, and caspase 3 activities of tetraoxane dimers. Bioorg Med Chem Lett. 2003;21(23):7392-7397.
37. Dong Y, Creek D, Chollet J, et al. Comparative antimalarial activities of six pairs of 1,2,4,5-tetraoxanes (peroxide dimers) and 1,2,4,5,7,8hexaoxonanes (peroxide trimers). Antimicrob Agents Chemother. 2007; 51(8):3033-3035.

38. Ellis GL, Amewu R, Sabbani RS, et al. Two-step synthesis of achiral dispiro-1,2,4,5-tetraoxanes with outstanding antimalarial activity, low toxicity, and high-stability profiles. J Med Chem. 2008;51(7): 2170-2177.

39. Kumar N, Singh R, Rawat DS. Tetraoxanes: synthetic and medicinal chemistry perspective. Med Res Rev. 2012;32(3):581-610.

40. Opsenica I, Opsenica D, Smith KS, Milhous WK, Solaja BA. Chemical stability of the peroxide bond enables diversified synthesis of potent tetraoxane antimalarials. J Med Chem. 2008;51(7):2261-2266.

41. O’Neill PM, Amewu RK, Nixon GL, et al. Identification of a 1,2,4,5-tetraoxane antimalarial drug-development candidate (RKA182) with superior properties to the semisynthetic artemisinins. Angew Chem. 2010;49(33):5693-5697.

42. Sharma D, Chetia D, Rudrapal M. Design, synthesis and antimalarial activity of some new 2-hydroxy-1,4-naphthoquinone-4-hydroxyaniline hybrid mannich bases. Asian J Chem. 2016;28(4):782-788.

43. Muregi FW, Ishih A. Next-generation antimalarial drugs: hybrid molecules as a new strategy in drug design. Drug Dev Res. 2010;71(1): 20-32.

44. Walsh JJ, Bell A. Hybrid drugs for malaria. Curr Pharm Des. 2009; 15(25):2970-2985.

45. Sashidhara KV, Avula SR, Palnati GR, et al. Synthesis and in vitro evaluation of new chloroquine-chalcone hybrids against chloroquineresistant strain of Plasmodium falciparum. Bioorg Med Chem. 2012; 22(17):5455-5459.

46. Sashidhara KV, Kumar A, Kumar M, Sarkar J, Sinha S. Synthesis and in vitro evaluation of novel coumarin-chalcone hybrids as potential anticancer agents. Bioorg Med Chem Lett. 2010;20(24):7205-7211.

47. Manohar S, Rajesh UC, Khan SI, Tekwani BL, Rawat DS. Novel 4-aminoquinoline-pyrimidine based hybrids with improved in vitro and in vivo antimalarial activity. ACS Med Chem Lett. 2012;3(7): 555-559.

48. Kumar A, Srivastava K, Raja Kumar S, Puri SK, Chauhan PM. Synthesis of 9-anilinoacridine triazines as new class of hybrid antimalarial agents. Bioorg Med Chem Lett. 2009;19(24):6996-6999.

49. Chadwick J, Amewu RK, Marti F, et al. Antimalarial mannoxanes: hybrid antimalarial drugs with outstanding oral activity profiles and a potential dual mechanism of action. Chem Med Chem. 2011;6(8):1357-1361.

50. Chauhan SS, Sharma M, Chauhan PM. Trioxaquines: hybrid molecules for the treatment of malaria. Drug News Perspect. 2010;23(10): 632-646.

51. Posner GH, McRiner AJ, Paik IH, et al. Anticancer and antimalarial efficacy and safety of artemisinin-derived trioxane dimers in rodents. J Med Chem. 2004;47(5):1299-1301.

52. Singh C, Malika H, Puri SK. Orally active amino functionalized antimalarial 1,2,4-trioxanes. Bioorg Med Chem Lett. 2004;14(2):459-462.

53. Singh C, Malika H, Puri SK. Synthesis and antimalarial activity of a new series of trioxaquines. Bioorg Med Chem Lett. 2004;12(5): 1177-1182.

54. Basco LK, Dechy-Cabaret O, Ndounga M, Meche FS, Robert A, Meunier B. In vitro activities of DU-1102, a new trioxaquine derivative against Plasmodium falciparum isolates. Antimicrob Agents Chemother. 2001;45(6):1886-1888.

55. Benoit-Vical F, Joe L, Berry A, et al. Trioxaquines are new antimalarial agents active on all erythrocytic forms, including gametocytes. Antimicrob Agents Chemother. 2007;51(4):1463-1472.

56. Loup C, Joe L, Benoit-Vical F, Meunier B. Trioxaquines and hemeartemisinin adducts inhibit the in vitro formation of hemozoin better than chloroquine. Antimicrob Agents Chemother. 2007;51(10): 3768-3770.

57. Sashidhara KV, Kumar A, Dodda RP, et al. Coumarin-trioxane hybrids: synthesis and evaluation as a new class of antimalarial agents. Bioorg Med Chem Lett. 2012;22(12):3926-3930. 
58. Araújo NCP, Barton V, Jones M, et al. Semi-synthetic and synthetic 1,2,4-trioxaquines and 1,2,4-trioxolaquines: synthesis, preliminary SAR and comparison with acridine endoperoxide conjugates. Bioorg Med Chem Lett. 2009;19(7):2038-2043.

59. Oliveira R, Newton AS, Guedes RC, et al. An endoperoxide-based hybrid approach to deliver falcipain inhibitors inside malaria parasites. Chem Med Chem. 2013;8(9):1528-1536.

60. Egan TJ. Haemozoin (malaria pigment): a unique crystalline drug target. Targets. 2003;2(3):115-124.

61. Foley M, Tilley L. Quinoline antimalarials: mechanism of action and resistance and prospects for new agents. Pharmacol Ther. 1998; 79(1):60-67.

62. Egan TJ, Marques HM. The role of haem in the activity of chloroquine and related antimalarial drugs. Coord Chem Rev. 1999;190-192:493-517.

63. Foley M, Tilley L. Quinoline antimalarials mechanisms of action and resistance. Int J Parasitol. 1997;27(2):231-240.

64. Paul M, O’Neill PM, Posner GH. A medicinal chemistry perspective on artemisinin and related endoperoxides. J Med Chem. 2004; 47(12):2945-2964.
65. Cumming JN, Ploypradith P, Posner GH. Antimalarial activity of artemisinin (qinghaosu) and related trioxanes: mechanism(s) of action. Adv Pharmacol. 1996;37:253-297.

66. O'Neill PM, Barton VE, Ward SA. The molecular mechanism of action of artemisinin-the debate continues. Molecules. 2010;15(3):1705-1721.

67. Golenser J, Waknine JH, Krugliak M, Hunt NH, Grau GE. Current perspectives on the mechanism of action of artemisinins. Int J Parasitol. 2006;36(14):1427-1441.

68. Zhang F, Gosser DK Jr, Meshnick SR. Hemin-catalyzed decomposition of artemisinin (qinghaosu). Biochem Pharmacol. 1992;43(8): 1805-1809.

69. Krungkrai SR, Yuthavong Y. The antimalarial action on Plasmodium falciparum, qinghaosu and artesunate in combination with agents that modulate oxidative stress. Trans R Soc Trop Med Hyg. 1987;81(5): 710-714.

70. Meshnick SR, Yang YZ, Lima V, Kuypers F, Kamchonwongpaisan S, Yuthavong Y. Iron-dependant free radical generation and the antimalarial artemisinin (qinghaosu). Antimicrob Agents Chemother. 1993; 37(5):1108-1114.
Drug Design, Development and Therapy

\section{Publish your work in this journal}

Drug Design, Development and Therapy is an international, peerreviewed open-access journal that spans the spectrum of drug design and development through to clinical applications. Clinical outcomes, patient safety, and programs for the development and effective, safe, and sustained use of medicines are the features of the journal, which

\section{Dovepress}

has also been accepted for indexing on PubMed Central. The manuscript management system is completely online and includes a very quick and fair peer-review system, which is all easy to use. Visit http://www.dovepress.com/testimonials.php to read real quotes from published authors.

Submit your manuscript here: http://www.dovepress.com/drug-design-development-and-therapy-journal 